\title{
ARTICLE
}

\section{Glacial ice and atmospheric forcing on the Mertz Glacier Polynya over the past 250 years}

P. Campagne ${ }^{1,2,3}$, Xavier Crosta ${ }^{1}$, M.N. Houssais ${ }^{2}$, D. Swingedouw ${ }^{1}$, S. Schmidt ${ }^{1}$, A. Martin² ${ }^{2}$ E. Devred ${ }^{3}$, S. Capo ${ }^{1}$, V. Marieu', I. Closset $^{2} \&$ G. Massé ${ }^{2,3}$

The Mertz Glacier Polynya off George V Land, East Antarctica, is a source of Adélie Land Bottom Water, which contributes up to $\sim 25 \%$ of the Antarctic Bottom Water. This major polynya is closely linked to the presence of the Mertz Glacier Tongue that traps pack ice upstream. In 2010, the Mertz Glacier calved a massive iceberg, deeply impacting local sea ice conditions and dense shelf water formation. Here we provide the first detailed 250-year long reconstruction of local sea ice and bottom water conditions. Spectral analysis of the data sets reveals large and abrupt changes in sea surface and bottom water conditions with a 70-year cyclicity, associated with the Mertz Glacier Tongue calving and regrowth dynamics. Geological data and atmospheric reanalysis, however, suggest that sea ice conditions in the polynya were also very sensitive to changes in surface winds in relation to the recent intensification of the Southern Annular Mode.

\footnotetext{
${ }^{1}$ EPOC, UMR CNRS 5805, Université de Bordeaux, Allée Geoffroy St Hilaire, Pessac 33615, France. ${ }^{2}$ LOCEAN, UMR CNRS/UPMC/IRD/MNHN 7159, Université Pierre et Marie Curie, 4 Place Jussieu, Paris 75252, France. ${ }^{3}$ TAKUVIK, UMI 3376 UL/CNRS, Université Laval, 1045 avenue de la Médecine, Quebec City, Quebec, Canada G1V OA6. Correspondence and requests for materials should be addressed to X.C. (email: x.crosta@epoc.u-bordeaux1.fr) or to G.M. (email: guillaume.masse@takuvik.ulaval.ca).
} 
A ntarctic Bottom Water (AABW) is considered as the great ventilator of the world deep ocean and is a critical component of the global climate system ${ }^{1,2}$. AABW is sourced by dense saline shelf waters, locally produced in several polynyas, where low sea ice concentrations (SICs) and open water conditions are maintained during winter and favour local sea ice and brine production ${ }^{3,4}$. Coastal polynyas are usually associated with the presence of local topographic or glacial features and synoptic-scale gravity winds ${ }^{4}$. Although they only represent a small fraction of the area covered by sea ice, polynyas are considered of key importance for the Earth climate system ${ }^{3,5}$. Indeed, while the 13 major Antarctic coastal polynyas only represent $\sim 1 \%$ of the maximum ice area, they are responsible for the production of $10 \%$ of the Southern Ocean sea ice ${ }^{3}$. Recently, it
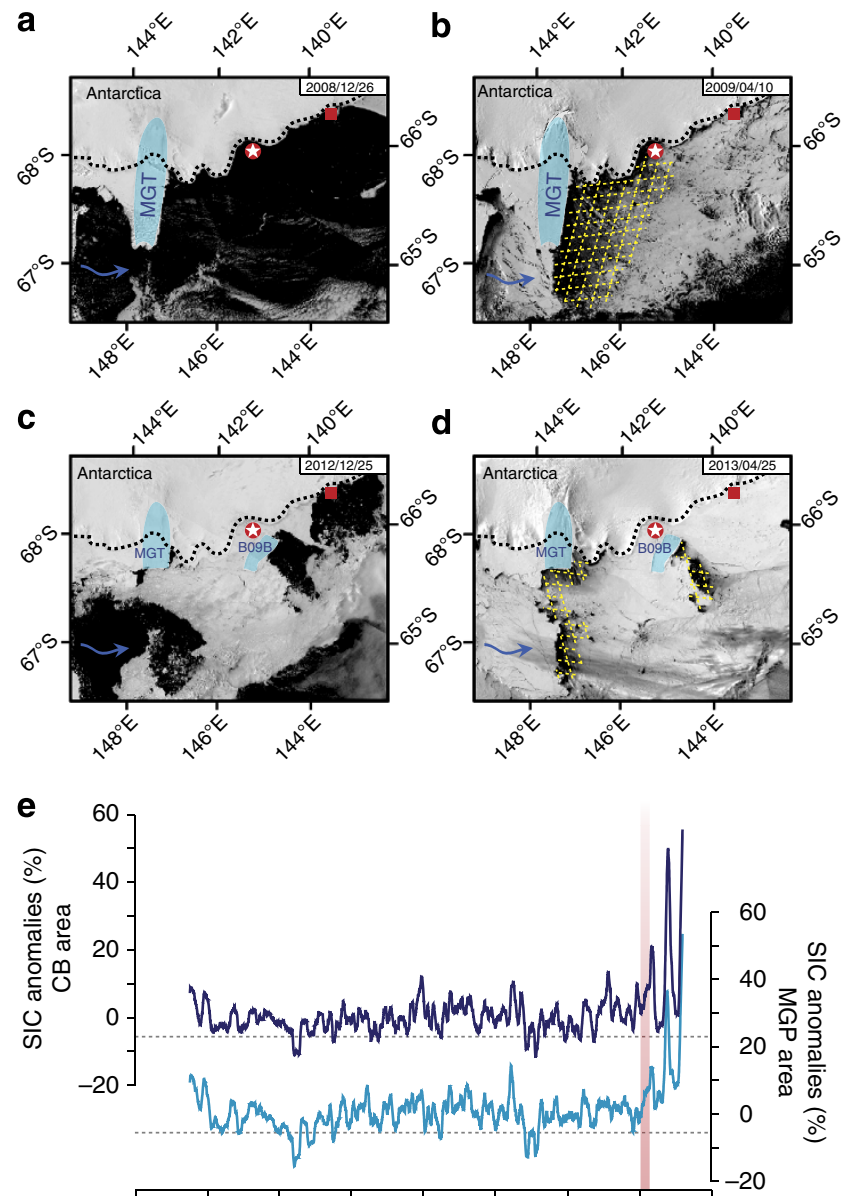

197519801985199019952000200520102015

Age (C.E.)

Figure 1 | Pre- and post-calving sea ice conditions in the George V Land. Aqua MODIS satellite images showing sea ice conditions in the study area during summer (a) and winter (b) before the 2010 calving event, and during summer (c) and winter (d) after the 2010 calving event. The white star in a red circle indicates the core location; the Dumont D'Urville station is indicated by a red square; blue shadings indicate glacial features, the MGT and the BO9B iceberg; the MGP area in winter before and after the calving is designated by the yellow grid on $\mathbf{b}, \mathbf{d}$; and the blue arrow indicates the general direction of the East Wind Drift; coastline is marked by the black dotted line. (e) Three-month averaged SSM/I time series of daily SIC anomalies in CB (dark blue) and in the Mertz area (MGP-light blue), for the period 1978-2012 C.E. (Common Era) using 1978-2009 as the reference period (for the exact grid points locations, see Fig. 7). The red shading indicates the 2010 calving event. has been shown that $\sim 25 \%$ of the AABW is sourced from the export of Adélie Land Bottom Water (ALBW) produced in the George V Land polynyas ${ }^{2,6}$. ALBW mainly originates from the Adélie Depression off the coast of George V Land ${ }^{3,6,7}$, where the Mertz Glacier (MG) Polynya (MGP) develops in winter along the western flank of the MG Tongue (MGT) and further extends to the West in the adjacent coastal bays (Commonwealth, Watt and Buchanan Bays; Fig. 1b; refs 8,9). The MGP constitutes the third most productive polynya in Antarctica, with a winter area of up to $6,000 \mathrm{~km}^{2}$ and an annual sea ice production of $120 \mathrm{~km}^{3}$ over the 1992-2001 period ${ }^{3,4}$.

Early in 2010, the MG underwent massive calving and lost half its tongue after collision with the B09B iceberg. The generation of an 80-km-long iceberg and subsequent retreat of the MG front had a profound impact on both regional icescape and ocean conditions $^{9-11}$. Satellite passive microwave data show that SIC increased by $50 \%$ (relative to the $1979-2009$ period) in the MGP area after the calving (Fig. 1e). Advection of thick consolidated sea ice and presence of fast ice downstream the MG in the MGP (Fig. 1c,d) led to a large reduction in sea ice production in the MGP, which in turn affected dense water formation ${ }^{9-11}$. Within 2 years following the calving, bottom water salinity decreased by over 0.30 psu in Commonwealth Bay $(\mathrm{CB})^{9}$.

Located in the southern part of the polynya, $\mathrm{CB}$ is ideal for studying past dynamics of the MGP and dense water formation'. Indeed, mooring observations and satellite data showed that oceanic and sea ice conditions (Fig. 1e) over the CB and MGP areas have experienced similar and synchronous pre- and postcalving changes over the recent years ${ }^{9}$. In addition, recent observations highlighting the presence of the saltiest waters of the Adélie depression in $\mathrm{CB}$ suggest that large production rates of dense shelf water occur in the bay 9,12 . Based on past expeditions, it has been suggested that the MG previously underwent similar calving events in the early part of the twentieth century ${ }^{13}$. However, these sporadic observations are insufficient to reconstruct past MGT dynamics with a high level of confidence.

In the present study, we provide a detailed reconstruction of surface and bottom oceanic conditions in the MGP over the last 250 years. This reconstruction is based on high-resolution analyses of diatom assemblages, diatom-specific biomarkers and major element abundances along a well-dated interface sediment core retrieved in January 2010 at CB (Fig. 1a; $66^{\circ} 54,38^{\prime}$ S$142^{\circ} 26,18^{\prime} \mathrm{E} ; 775 \mathrm{~m}$ depth). This study represents the first detailed assessment of the MG-MGP system dynamics over the last few centuries, and therefore provides essential information on how the system recovers after major perturbations such as calving events. We also evaluate the impact of the recent positive shift in the Southern Annular Mode (SAM) on MGP surface conditions through a century-long atmospheric reanalysis.

\section{Results}

Multidecadal trends of sea surface conditions. Variations of Fragilariopsis cylindrus populations and di-unsaturated highly branched isoprenoid (HBI) lipid [HBI:2] abundances characterize spring sea ice occurrence ${ }^{14,15}$, while summer open ocean conditions are inferred from high abundances of open water diatoms ${ }^{16}$ (see Methods section). Titanium (Ti) content is used here to infer changes in terrigenous supply to the ocean ${ }^{17}$, thus reflecting the variability of the terrigenous delivery by glacial melting, the dominant process in Antarctic coastal areas at such timescale ${ }^{18,19}$. High (low) relative abundances of open water diatoms are concomitant with high (low) contents of $\mathrm{Ti}$ and, conversely, with low (high) relative abundances of F. cylindrus and low (high) concentrations of [HBI:2] (Fig. 2). Minimum abundances of [HBI:2] and F. cylindrus associated with maxima 


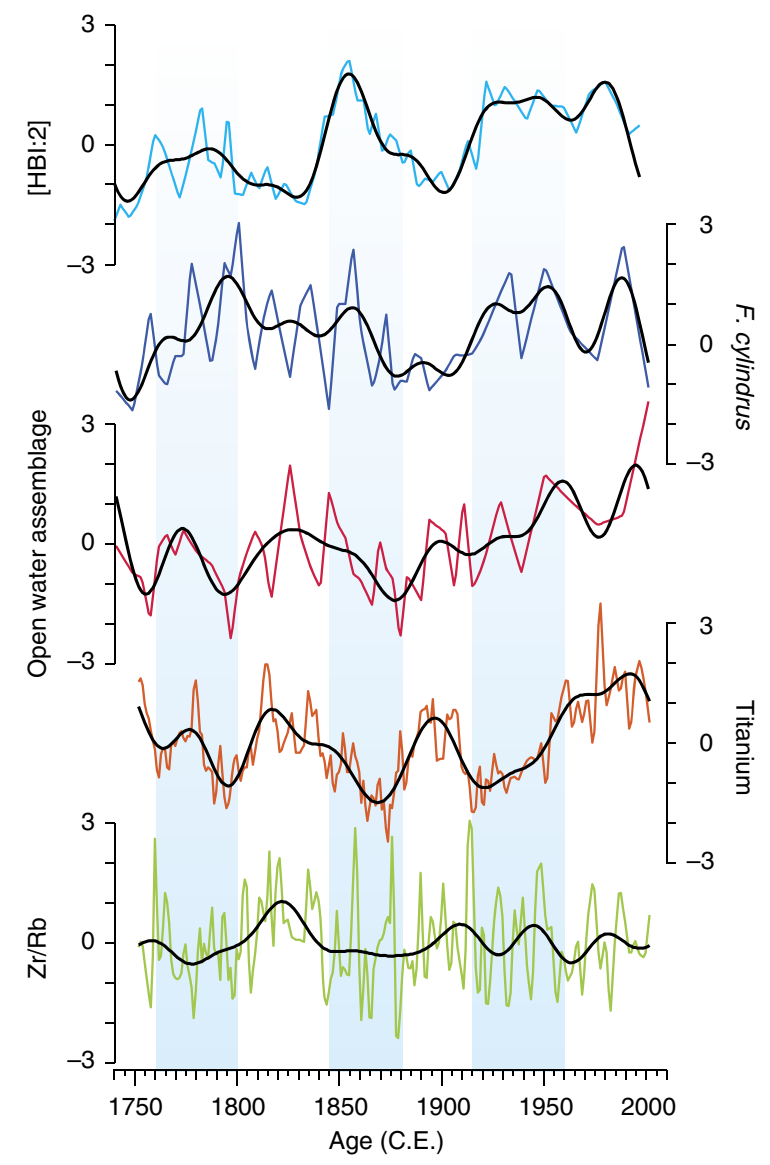

Figure 2 | Sea ice and ocean conditions in CB over the last 250 years. Sea ice proxies: standardized concentrations of $\mathrm{HBI}: 2$ (light blue) and relative abundances of $F$. cylindrus (dark blue). Open water proxies: standardized relative abundances of open water diatom group (red) and titanium content (orange). Bottom current variability: standardized $\mathrm{Zr} / \mathrm{Rb}$ ratio (green). Black curves represent the low-pass-filtered data, with a cutoff frequency at 1/32 (in year). The blue shadings indicate decades following each calving event with marked increase in SIC in the CB area.

of open water diatoms and Ti during 1740-1760, 1800-1845 and 1880-1915 periods (Fig. 2), therefore indicate the presence of a well-developed polynya characterized by low SIC during the winter, early spring sea ice retreat and long summer season. The presence of a well-developed MGP promoted intense sea ice formation during winter and enhanced brine-induced convection. Variations in bottom current velocities were estimated from changes in sediment grain size inferred from Zirconium versus Rubidium $(\mathrm{Zr} / \mathrm{Rb})$ relative abundances ${ }^{20}$. Assuming that greater deep-reaching convection is associated with intensified bottom currents, the high $\mathrm{Zr} / \mathrm{Rb}$ ratios (Fig. 2) recorded during periods of well-developed MGP suggest enhanced bottom currents favouring a coarse sedimentation at the core location. In contrast, the 1760-1800, 1845-1880 and 1915-1960 periods are characterized by maxima in [HBI:2] and F. cylindrus relative abundances and minima in open water diatoms, $\mathrm{Ti}$ and $\mathrm{Zr} / \mathrm{Rb}$ records (Fig. 2). This reflects the presence of heavier sea ice conditions in spring, leading to shorter growing seasons and cooler summers, associated with reduced inputs from glacial runoffs and melting. During these intervals, a reduction of the MGP area and sea ice production coincided with a weaker bottom circulation, as revealed by the presence of finer (low $\mathrm{Zr} / \mathrm{Rb}$ ) sediments. Our records therefore suggest that since the mid- eighteenth century, surface ocean conditions and MGP activity alternated between periods of high sea ice presence and periods of prolonged open ocean conditions.

Cyclic pattern. These multidecadal trends of the MG-MGP system are further characterized by a strong asymmetric evolution with sharp increases in SIC at $\sim 1760, \sim 1845$ and $\sim 1915$, followed by a slow decrease over the subsequent decades (Fig. 2). A similar sharp increase observed after the 2010 calving event (Fig. 1e) suggests that, at least for the past 250 years, these asymmetric oscillations ( $\sim 70$ years periodicity) are related to a series of large calving events. Each of these events probably induced a rapid closing of the MGP as the loss of the ice tongue allowed for sea ice transported within the East Wind Drift to enter the area.

This scenario is further supported by the wavelet analysis of our data set, which shows that all variables exhibit a common high power in the 60-80 year band, throughout the entire record (Fig. 3). Although such periods (60-80 years) are close to the limit of detection (the bottom of the cone influence), they are characterized by a high statistical significance level of the period (95\%, according to ref. 21). In addition, in the 60-80 year band, a positive correlation, characterized by rightward pointed arrows, is shown by cross-wavelet analyses (see Methods section) between sea ice proxies (Fig. 3a) and between open water proxies (Fig. 3b). In contrast, as indicated by leftward pointed arrows, negative correlations occur in the 60-80 year band when comparing sea ice versus open water proxies (Fig. $3 \mathrm{c}-\mathrm{f}$ ). Interestingly, continuous wavelet transforms indicate that open water and sea ice diatom signals (Supplementary Fig. 1) exhibit an additional $\sim 20-25$ year cyclicity, which is absent from the geochemical proxies. Although the causes remain unclear, differences in the spectral pattern of diatom and geochemical records may be attributed to the origin of the proxies themselves. The [HBI:2] is synthesized by diatoms living within or attached to sea ice. As such, we expect a direct response of [HBI:2] to SIC and the timing of ice waning ${ }^{14}$. Sea ice-related diatoms such as F. cylindrus thrive at the sea ice margin while open water diatoms thrive in the water column. Therefore, we believe that diatoms respond to both the timing of sea ice waning and oceanic biotic and abiotic factors such as stratification, upwelling and the injection of warmer waters ${ }^{15-17}$, which are expressed at shorter timescales ${ }^{22,23}$.

Barrier effect of the MG. Each calving event is characterized by relatively elevated abundances of the sea ice proxies for a couple of decades, followed by a slow decrease of the sea ice proxies and a concomitant increase of the open water proxies. These results suggest that each event was followed by a slow and constant readvance of the glacier, but that a few decades are necessary for the tongue to reach a sufficient length to prevent sea ice advection in the area. As such, during few decades after 1800, 1880 and 1960 (Fig. 2), the tongue probably acted as a barrier and deflected the East Wind Drift pack ice northward, thus restoring favourable conditions for the establishment of the polynya. Although only limited observations exist to reconstruct the recent history of the MGP, it is clear that at least one major calving event occurred between 1912, when the Australasian Antarctic Expedition led by Mawson (1911-1914) measured a 150-km-long tongue from the grounding line, and 1958, when the Soviet Antarctic Expedition reported a $113-\mathrm{km}$-long tongue ${ }^{13}$. The sharp increase in sea ice proxies in 1915 strongly suggests that this event occurred only a few years after Mawson's expedition. Given the mean growth rate of the tongue of $\sim 1 \mathrm{~km}$ per year ${ }^{24}$, the glacier had presumably reached $\sim 150-160 \mathrm{~km}$ at that time when it calved. This length is similar to the one reached by the glacier before the 2010 


\section{a}

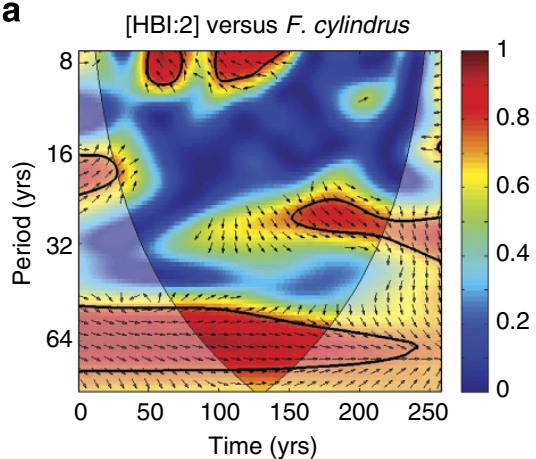

c

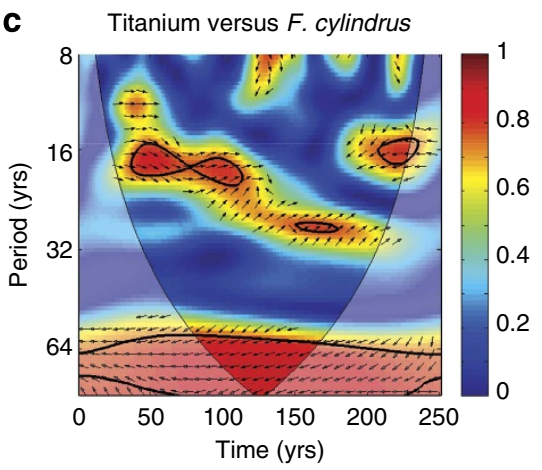

e Open water diatoms versus $F$. cylindrus

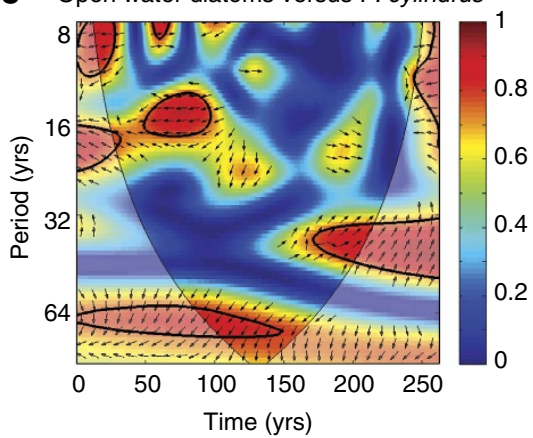

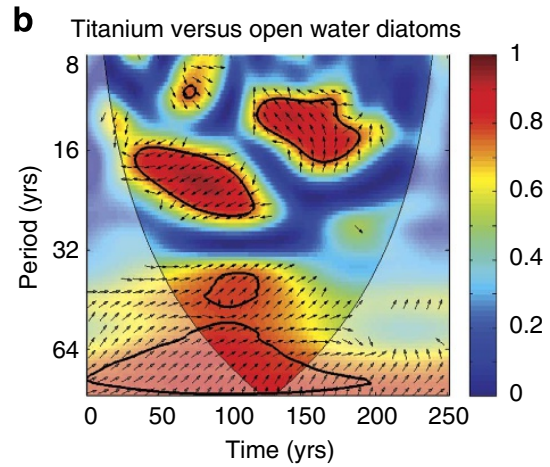

d $[\mathrm{HBI}: 2]$ versus open water diatoms

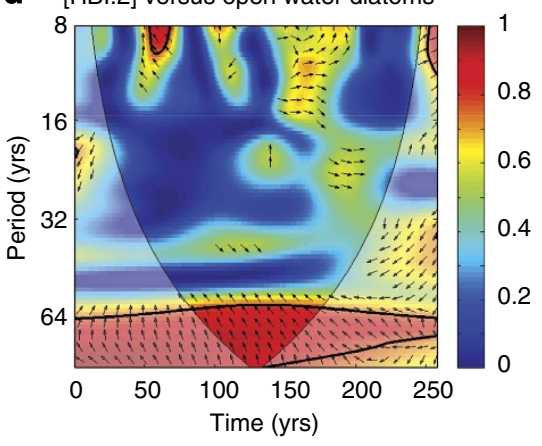

f

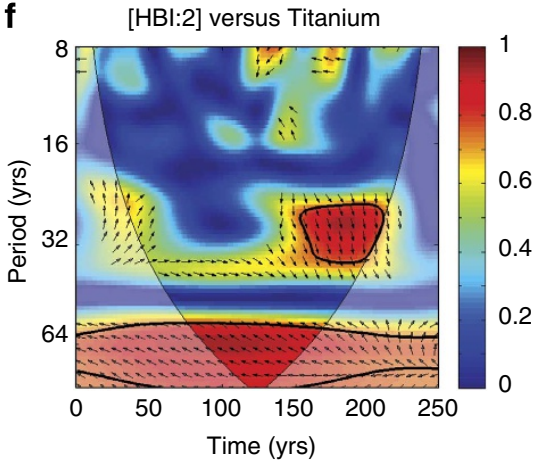

Figure 3 | Relationship between proxies and cyclicity of sea surface conditions in the MGP area. Cross-wavelet transform (XWT) on the sedimentary proxies (using Morlet wavelet and Monte Carlo methods ${ }^{21}$ ) between (a) [HBI:2] versus F. cylindrus; (b) Ti versus open water diatoms; (c) Ti versus F. cylindrus; (d) [HBI:2] versus open water diatoms; (e) open water diatoms versus F. cylindrus; and (f) [HBI:2] versus Ti. Statistically significant periods are identified by the black circled red zones. Rightward pointed arrows indicate positively correlated signals while leftward pointed arrows indicate negatively correlated signals. Yrs, years.

calving ${ }^{25,26}$ and is in line with Mawson's observations in 1912. If the MGT lost half $(80 \mathrm{~km})$ of its length, similar to the 2010 calving event, it would have taken $\sim 40$ years for the tongue to grow back from $\sim 80 \mathrm{~km}$ in 1915 to $113 \mathrm{~km}$, based on the Soviet Antarctic Expedition in 1958. These results suggest that from the $1960 \mathrm{~s}$, the ice tongue was then long enough to effectively act as a barrier for drifting ice. In the 1990s, signs of imminent calving were already detected with the formation of two major rifts near the glacier grounding line and the front of the glacier grounding on the Mertz Bank to the north ${ }^{13,25}$. The shallow bathymetry of the bank (Supplementary Fig. 2) enhances local tidal currents exerting lateral stress on the tip of the glacier, likely impacting the tongue along-flow velocity ${ }^{26}$. In addition, the presence of several icebergs released by upstream glaciers and grounded onto the Mertz bank ${ }^{13,26}$ probably further increases the lateral distortion of the tongue. As such, it appears that beyond a threshold of $\sim 150-160 \mathrm{~km}$, lateral stresses exerted on the sides and at the lie of the tongue lead to its rupture.
Recent changes in seasonality. Interestingly, the analysis of the upper sediment section show that while the MGT was sufficiently long to promote open water conditions in the lie of the glacier during the last 50 years, both [HBI:2] and F. cylindrus remained relatively abundant in the sediments (Fig. 2). In addition, $\mathrm{Zr} / \mathrm{Rb}$ values did not show a marked increase as expected during this phase (Fig. 2). This suggests that, in contrast to previous cycles, pre-calving conditions over recent decades were characterized by a more persistent sea ice cover during spring and were associated with weaker bottom water circulation than observed during previous cycles. We also note higher $\mathrm{Ti}$ contents (terrigenous inputs) along with greater abundances of open water diatom species (and in particular large centric diatoms; Fig. 4), suggesting strong glacial melting and more persistent open water conditions led by warmer surface waters during summer over the recent decades. Warmer open water conditions during the summer are further confirmed by the large peak of a specific HBI isomer [HBI:3] during the past 40 years (Supplementary Fig. 3). High 


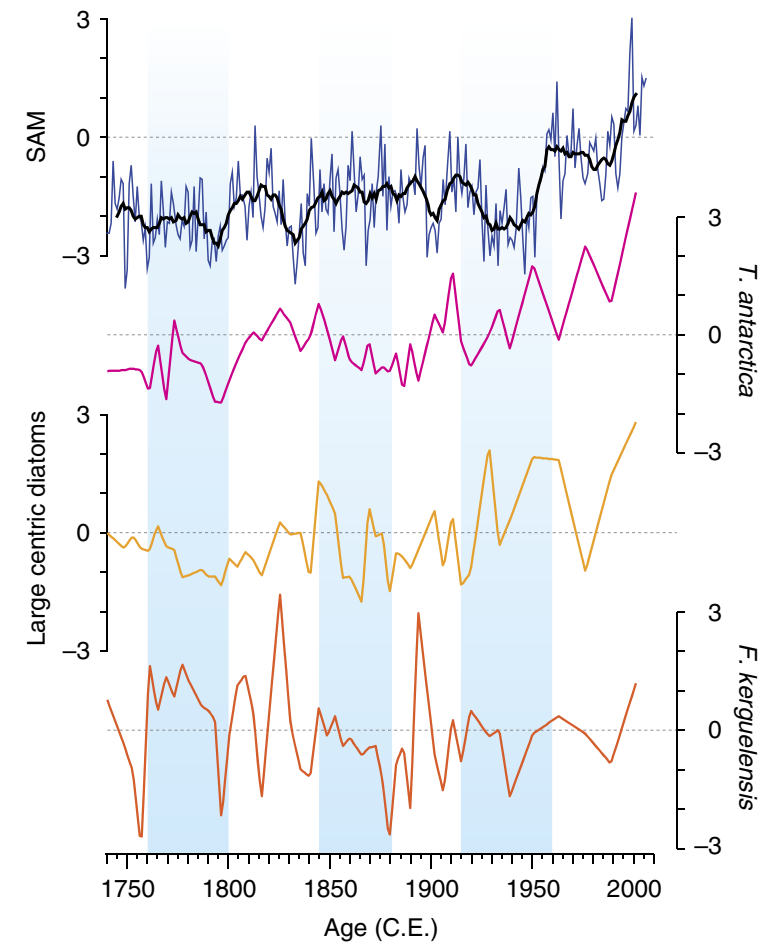

Figure 4 | Atmospheric forcing and impacts on the sea ice free season during the instrumental period in the MGP area. Evolution of the SAM according to the reconstructed Marshall index (blue, annual values and black, 11 years moving average) over the last 250 years ${ }^{31}$. Open water proxies: standardized relative abundances of $T$. antarctica sp (pink), large centric diatom group (yellow; see Methods section for species composition) and F. kerguelensis (orange). The blue shadings indicate decades following each calving event with marked increase in SIC in the $\mathrm{CB}$ area.

abundances of [HBI:3] in sediments reflect the contribution of phytoplanktonic-derived organic matter ${ }^{14}$, and thus indicate a higher phytoplankton productivity during the summer (Supplementary Note 1). Overall, these results therefore provide strong evidence for changes occurring over the growing season in recent decades. From our records, this apparent shift in seasonality is characterized by cooler and icier springs, warmer and more open summers in line with recent atmospheric and oceanic observations from other areas in the Southern Hemisphere ${ }^{22,27}$.

\section{Discussion}

Our results strongly suggest that surface oceanic conditions and dense shelf water production are closely related to the MGP presence and activity. Reasons for the $\sim 70$ years cyclicity of the MGP are still not fully understood but, given the major constraints of the local topography, it is likely that these cycles are set by the rate of advance and along-flow velocity of the MG. However, according to several studies ${ }^{13,25}$, icebergs released from upstream outlet glaciers (for example, Ninnis Glacier) could have impacted the stability of the MGT when they grounded and/or passed through the area. In addition, when the tongue is too short to constitute a barrier, these icebergs can impact the regional oceanography for several years, leading to a temporary increase in sea ice conditions, as observed since 2010 with the presence of the B09B iceberg in front of CB (Fig. 1c,d). The resolution of our records, however, does not allow us to capture such phenomena, if they ever occurred in or around $\mathrm{CB}$ in the past. Our data also indicate a close relationship between the MG history and MGP dynamics between 1740 and 1960 . However, since the 1960s, our records suggest unexpectedly cool and icy springs at a time where the MGT should have reached a sufficient length to promote the presence of a well-established MGP.

We propose that, superimposed on the large multidecadal oscillations generated by the MG dynamics, additional factors contributed to modulating sea surface conditions in the area. The SAM, principal mode of atmospheric variability over the Southern Ocean $^{28}$, has shown a steadily increasing index over the last 50 years (refs 27,29; and Figs 4 and 5a), with a more positive trend in summer ${ }^{27,30}$. Reconstructions indicate that this increase is unprecedented over the last few centuries ${ }^{31}$ possibly due to ozone depletion and a rise in greenhouse gases ${ }^{29,32}$, and recent investigations have argued that such trend had a direct influence on sea surface conditions in several regions around Antarctica through modulation of the wind pattern $22,23,29,33-35$. The recent positive trend in the SAM index is indeed associated with an intensification of the polar vortex ${ }^{32}$ leading to a southward shift of enhanced circumpolar westerlies ${ }^{28}$. This, in turn, led to a more intense Antarctic Circumpolar Current $(\mathrm{ACC})^{35}$ and associated ocean eddy activity ${ }^{36}$. We postulate that such large-scale changes impacted the sea ice distribution in spring, modified the summer off-shelf ocean circulation due to changes in the large-scale wind stress pattern and are the dominant cause for the contrasted response of the Adélie Land continental shelf over the last 50 years.

Indeed, several studies have evidenced a close link between the planetary circulation in the southern polar atmosphere and the katabatic wind regime, the latter being part of the large-scale meridional tropospheric circulation over Antarctica ${ }^{37-40}$. Observations in East Antarctica revealed that an intensified tropospheric vortex was associated with weakened katabatic winds over the Antarctic margin ${ }^{40}$, and analysis of the atmospheric wind fields during the last 140 years from the twentieth century reanalysis (20CR) reanalysis ${ }^{41}$ confirms a significant westward shift of the wind pattern in the George $\mathrm{V}$ Land over recent decades (Fig. 5a, green curve; and Supplementary Note 2). A weakening of the meridional wind circulation and thus increasing zonal circulation over the last decades as suggested by refs 40,42 have also been observed in the region $^{34,43}$. Indeed, at seasonal to inter-annual timescales, sea ice conditions in the MGP area have been shown to be sensitive to the latitudinal location of the Antarctic Circumpolar Trough and associated to more along shore wind transport ${ }^{34,43}$. In the present scenario, reduction of katabatic winds intensity over the MGP area would weaken the northward transport of sea ice, resulting in the retention of more ice within the area. The latter would delay the onset of sea ice melt in spring in agreement with higher sea ice proxies in our record since 1960. Although based on a restricted number of data points, a reduction of sea ice proxies in the uppermost sediment sections suggests a recent tendency towards a more reduced sea ice cover in spring, which is in line with the recent analysis of the sea ice seasonality in the area using the satellite records ${ }^{44}$

Our data also indicate warmer sea surface conditions during summer over recent decades. As recently observed in several Antarctic regions, it is argued here that intrusions of warm Circumpolar Deep Water (CDW) onto the continental shelf promoted open water conditions and higher sea surface temperatures $7,23,33,45$. Increasing CDW contribution onto the Antarctic Peninsula shelf was linked to the recent changes in the strength of the $\mathrm{SAM}^{46}$. Indeed, modelling studies have shown that advection of CDW onto the Antarctic continental shelf is linked to enhanced upwelling southward of the ACC, promoted by a southward shift and strengthening of the Southern Ocean Westerlies ${ }^{35,47}$. Surface wind stress curl calculated from the 

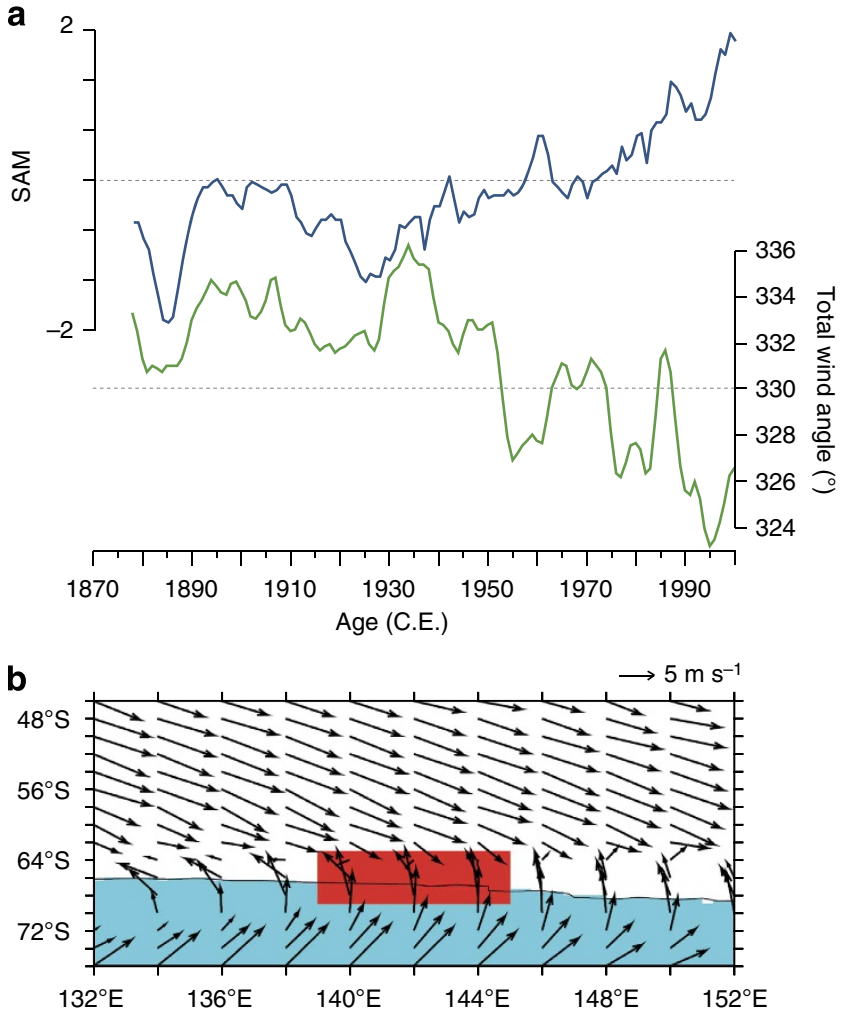

Figure 5 | Evolution of the SAM and of the wind pattern over the AdélieGeorge V Land since the nineteenth century. (a) Standardized values of SAM index (5 years running mean; blue), computed in the $20 \mathrm{CR}$ reanalysis following ref. 70 and the total wind direction angle at $2 \mathrm{~m}$ (green; ${ }^{\circ}$ ) computed in the red box of the lower panel using the same reanalysis. The North direction indicates the $0^{\circ}$ modulo $360^{\circ}$ and the angle is counted positively clockwise. (b) Annual mean wind speed from 20CR reanalysis averaged over the period 1871-2010. The red box indicates the study area where the wind have been computed in $\mathbf{a}$.

20CR reanalysis indeed suggests long periods of strong positive trend in upwelling-favourable vertical velocities with positive values starting roughly after 1950, concomitant with the SAM trend (Supplementary Fig. 4 and Supplementary Note 2). In the Mertz region, in contrast with West Antarctica, flooding of the shelf by the CDW occurs as synoptic weather timescale intrusions rather than as a continuous flow ${ }^{7}$. However, the proximity of George V Land continental shelf to the southern ACC boundary facilitates transport of CDW into the Mertz region ${ }^{48}$, as suggested in other Antarctic areas ${ }^{23}$, providing that adequate dynamical forcing exists to drive this water mass on the shelf. According to ref. 49 , a number of mechanisms involving interaction of the zonal flow with the topographic troughs disseminated along the Antarctic shelf break are likely to favour such transport. While some of these may be linked to the internal variability of the flow $^{50}$, some would be the result of enhanced wind-driven zonal flow. We note that, off the Adélie Land shelf, a more zonal wind pattern in the 20CR reanalysis (Fig. 5) over recent decades was concomitant to the southward shift (Supplementary Fig. 5) and the strengthening ${ }^{35,47}$ of the Westerlies at mid latitudes. Increasing zonal wind circulation poleward may have contributed to accelerate the westward flowing Antarctic Slope Current, the southern branch of the Australian Antarctic Basin cyclonic circulation ${ }^{51,52}$, thus favouring the inflow of CDW through nonlinear momentum advection onto the shelf trough. Recent observations suggest that a weaker and more zonal circulation promote uplift and enhanced onshore intrusion of $\mathrm{CDW}^{45}$, and studies attributed an increased abundance of terrigenous particles in the sediments to enhanced melting of both continental and sea ice during periods of increased advection of warm CDW onto the shelf ${ }^{17-19,53}$. The high terrigenous content recorded in CB2010 since 1960 (Fig. 2) can therefore be interpreted as a result of enhanced melting of regional glaciers in response to increased advection of warm CDW onto the shelf. This enhanced melting of glacial ice could also be contributing to further freshening the ALBW as reported by Lacarra et al. ${ }^{9}$

Our results demonstrate that, in response to glacial dynamics and local physiography, recurrent massive calving events of the MG occurred over the last 250 years. These events had profound impacts on ocean surface conditions and dense water production of the downstream polynya. Taking into consideration that many of these glacier-polynya systems are disseminated around Antarctica $^{4}$ and that dense shelf water is ultimately a precursor of AABW, whose impact on large-scale ocean circulation is well known ${ }^{1,2}$, our study provides evidence that local processes may contribute to alter global ocean and climate systems. In contrast to previous cycles, our data indicate that during the last 50 years, the region was experiencing a more compact sea ice cover, a larger supply of glacial meltwater and a slowdown of bottom currents. These results suggest a reduction of dense water production and are consistent with the long-term freshening of the ALBW observed in the Australian Antarctic Basin since the late 1960s (refs 54,55). This contrasted response of the MGP region during the last Mertz cycle may just be a transitory phenomenon as the SAM increase over that period is thought to be partly due to ozone depletion in the polar vortex. Since studies are predicting that the ozone hole will replenish in the future decades $^{56}$, natural multidecadal glacier cycles such as those identified in our records are likely to take over.

\section{Methods}

Sediment material and chronology. A 30.5-cm-long interface core was retrieved aboard the R/V Astrolabe $\left(66^{\circ} 54.38^{\prime} \mathrm{S} ; 142^{\circ} 26.18^{\prime} \mathrm{E} ; 775 \mathrm{~m}\right.$ water depth) during the 2010 COCA cruise. Positive X-ray images performed on the SCOPIX imageprocessing tool ${ }^{57}$ gave detailed information on sediment density and structure. SCOPIX images revealed that, in contrast to high accumulation sites from Dumont d'Urville Trough, sediments from CB were massive with no signs of laminations. The core was sampled continuously at $0.5 \mathrm{~cm}$ resolution and its chronological framework was determined based on ${ }^{210} \mathrm{~Pb}$ excess $\left({ }^{210} \mathrm{~Pb}_{\mathrm{xs}} ; T_{1 / 2}=22.3\right.$ years $)$, which is rapidly incorporated into the sediment from atmospheric fallout and water column scavenging. The activities of ${ }^{210} \mathrm{~Pb}$ and ${ }^{226} \mathrm{Ra}$ were measured on dried sediments by non-destructive gamma spectrometry using a well-type, highefficiency low-background detector equipped with a Cryo-cycle (CANBERRA). Activities are expressed in $\mathrm{mBq}^{-1}$ and errors are based on 1 s.d. counting statistics (Fig. 6). ${ }^{210} \mathrm{~Pb}_{\mathrm{xs}}$ was determined by subtracting the activity supported by its parent isotope, ${ }^{226} \mathrm{Ra}$, from the total ${ }^{210} \mathrm{~Pb}$ activity in the sediment. Mass accumulation rate $\left(0.025 \mathrm{~g} \mathrm{~cm}^{-2} \mathrm{y}^{-1}\right)$ was calculated from the sedimentary profiles of ${ }^{210} \mathrm{~Pb}_{\mathrm{xs}}$, plotted against cumulative mass. The deposition time (in years) was obtained by dividing the cumulative dry mass per unit area by mass accumulation rate. The deposition year for each sediment layer was subsequently estimated based on the 2010 sampling date for the sediment-water interface.

Diatoms. Micropaleontological analyses were performed according to the methodology described in ref. 58. For each sample, 300-350 diatom valves were counted and data are presented as species relative abundances. Briefly, diatom identification was performed to the species or species group level at a $\sim 5$-year resolution. Sixtyeight diatom species were identified in down-core assemblages, from which only a dozen species presented abundances higher than $2 \%$ of the total diatom population. Only these species were considered relevant for reconstructing environmental changes. Diatom species or species groups we confront here experience similar ranges of variability in CB2010, $2.5-13 \%$ for F. cylindrus, $\sim 1-9 \%$ for F. kerguelensis and $\sim 0-7 \%$ for the large centric group and Thalassiosira antarctica abundances, respectively (Supplementary Fig. 6).

F. cylindrus is one of the most common diatoms found along the Adélie Land margins $s^{59}$ as it thrives within stratified sea ice-covered waters ${ }^{15}$. Large abundances of F. cylindrus in sediments indicate the presence of a sea ice cover persisting over 7.5 months per year ${ }^{15}$. In contrast, the open water diatom 


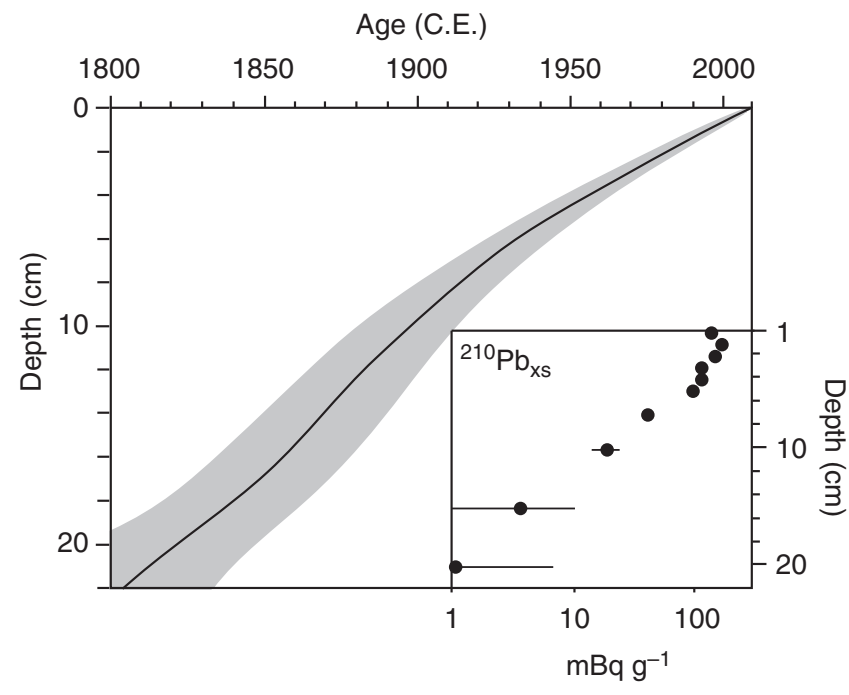

Figure 6 | CB2010 chronology. CB2010 age model (dark line) based on ${ }^{210} \mathrm{~Pb}$ excess $\left({ }^{210} \mathrm{~Pb}_{\mathrm{xs}}\right)$ and associated age-model errors (grey area). The inset corresponds to the down-core profile of ${ }^{210} \mathrm{~Pb}_{\mathrm{xs}}$ (error bars correspond to $1 \mathrm{~s}$.d.).

assemblage, composed by F. kerguelensis and large centric diatoms, characterizes open water conditions during summer ${ }^{16}$

F. kerguelensis dominates assemblages of the open ocean zone south of the Polar Front where sea ice is absent during summer ${ }^{60}$. Similarly, high abundances of large centric diatom species, such as T. lentiginosa or T. oliverana, commonly occur in the Southern Ocean south of the Polar Front in areas characterized by permanent open ocean conditions ${ }^{16,61}$. Relative abundances of $T$. lentiginosa show an inverse relationship with sea ice cover with high occurrences between 0 and 4 months of sea ice presence per year and a decline towards prolonged sea ice duration ${ }^{16}$. T. oliverana is clearly dominant in locations where open ocean conditions to sea ice edge during summer occur ${ }^{16}$. T. antarctica has been described as a dominant species within diatom assemblages in non-stratified or weakly stratified Antarctic surface waters ${ }^{62}$. T. antarctica blooms in open waters during summer-autumn, and produces resting spores at the end of the growing season when sea ice returns ${ }^{63}$. T. antarctica resting spores, the main form encountered in sediments, is most abundant in regions where sea ice is present for at least 6 months per year, and is believed to be induced under nutrient-stressed conditions or low light intensities ${ }^{15}$.

Geochemical data. Few marine and freshwater diatoms belonging to Haslea, Navicula, Pleurosigma and Rhizosolenia genera were recently found to be synthesizing HBIs ${ }^{14,64}$. A di-unsaturated isomer [HBI:2] has been identified in Antarctic sea ice and isotopic analyses provide evidence for that this isomer to be synthesized by sea ice dwelling diatoms. In contrast, tri-unsaturated HBI isomers [HBI:3] have been identified in water column phytoplankton ${ }^{14}$. Recent studies have proposed the use of [HBI:2] and [HBI:3] to reconstruct variations of Holocene Antarctic sea ice duration as complementary sea ice proxy to diatom counts ${ }^{65}$. Biomarker analysis followed the technique described by ref. 14 and were performed every $0.5 \mathrm{~cm}$ through the core. Briefly, an internal standard was added to the freeze-dried sediments, lipids were extracted using a dichloromethane/methanol mixture to yield a total organic extract, which was then purified using open column chromatography (silica). Hydrocarbons were analysed using a gas chromatograph coupled to a mass spectrometry detector.

$\mathrm{Ti}$ and $\mathrm{Zr}$ are considered to be direct indicators of terrigenous inputs as these elements are not involved in biological cycles ${ }^{17}$. In the literature, variations in $\mathrm{Ti}$ content are largely used to infer past changes in terrigenous supply to the ocean ${ }^{17}$. Microfabric analysis of sediment in the Mertz-Ninnis and Adélie troughs show that both terrigenous content and $\mathrm{Ti}$ content are low in spring laminae and increase over the growing season (when open water diatoms dominate the siliceous assemblage) and during which the summer glacial melting is high ${ }^{17,53,66}$. Indeed, in Antarctic coastal areas, delivery of terrigenous particles is possible via several dominant modes as meltwater discharge, ice rafting, runoff from outlet glaciers and aeolian transport, although this latter source is considered negligible in coastal East Antarctic regions ${ }^{17-19}$. Variations in $\mathrm{Zr}$ to $\mathrm{Rb}$ content ratio track changes in sediment grain size, where $\mathrm{Zr}$ represents the coarsest sediment fraction and $\mathrm{Rb}$ represents the finest ${ }^{20}$. Ti, Zr and $\mathrm{Rb}$ contents were measured on slab sections at a $2 \mathrm{~mm}$ resolution along the entire core using an AAVATECH XRF core-scanner ${ }^{67}$.

Satellite data. Daily SICs for the time period 1978-2012 were obtained from the National Snow and Ice Data Center data repository. The data set is based on passive microwave observations from the Nimbus-7 SSMR (1978-1987), DMSP

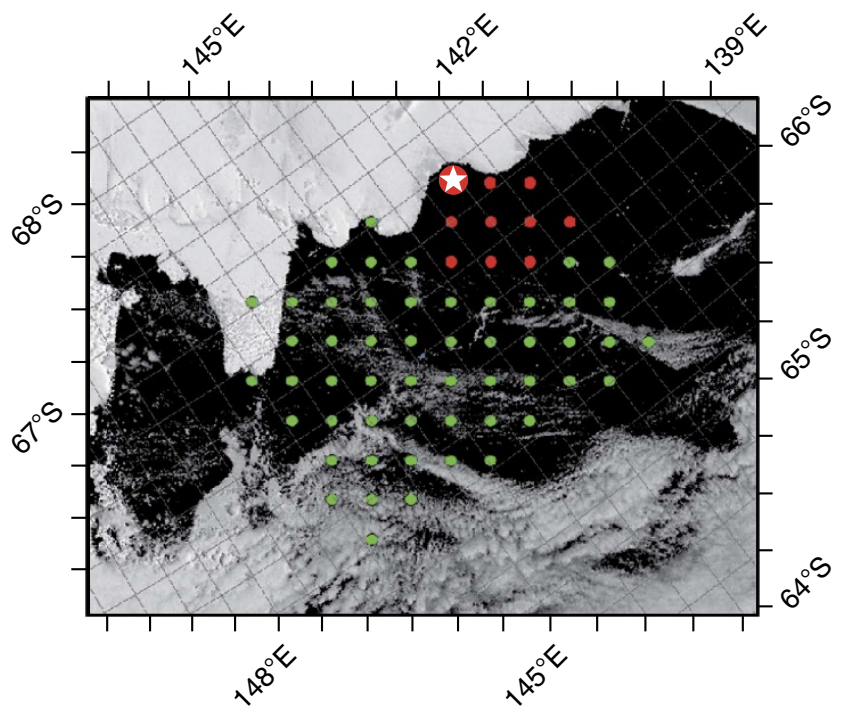

Figure 7 | Pixels locations for extraction of SICs. MODIS satellite image $(2008 / 12 / 26)$ of the George $V$ Land indicating the grid points used for the extraction of the daily SIC values: white star in a red circle indicates the core location; red spots correspond to the $\mathrm{CB}$ area and green spots represent the MGP area.

SSM/I (1987-2007) and SSMIS (2007-2012) radiometers processed with the NASA Team algorithm ${ }^{68}$ at a spatial resolution of $25 \times 25 \mathrm{~km}$. Averaged concentrations were calculated over two specific domains, CB and the entire MGP domain (Fig. 7). Daily anomalies were calculated using the average of the pre-calving 1978-2009 period and then low-pass filtered using a 3-month moving average (Fig. 1e). SIC data were standardized. Anomalies represent differences between the daily value and the mean daily value calculated over the reference period.

Spectral analysis. Unlike many traditional mathematical methods (for example, Fourier analysis), the wavelet approach can be used to analyse time series that contain non-stationary spectral power at many different frequencies ${ }^{21}$. For geological time series, although visual comparison of plots is commonly used, cross-wavelet analysis permits detection, extraction and reconstruction of relationships between two non-stationary signals simultaneously in frequency (or scale) and time (or location) ${ }^{69}$. The continuous wavelet transform (CWT; Supplementary Fig. 1) of time series is its convolution with the local basis functions, or wavelets, which can be stretched and translated with flexible resolution in both frequency and time. The principle of cross-wavelet analysis and the complete method we used are described in ref. 21. We used the MATLAB package for cross-wavelet analysis written by Grinsted et al. ${ }^{21}$ and applied the Morlet wavelet as the mother function on our data set. This method provides a good balance between time and frequency localization, and we used Monte Carlo simulations to provide frequency-specific probability distribution (global wavelet spectrum) that can be tested against wavelet coefficients. Statistical significance was estimated against a red noise model ${ }^{21}$. In this study, to test the relevance of our proxies, their statistical relationships and to examine periodicities in a frequency domain, we compared the two time series by their CWTs, which we hypothesized are linked in some way. The resulting cross wavelet transform (XWT, Fig. 3) exposed their common power and relative phase in time-frequency space of the two signals. Data were previously standardized, which did not introduce any change in the shape of the records but normalized the amplitude of the variations (Supplementary Fig. 6).

Atmospheric reanalysis. To analyse the Southern Hemisphere atmospheric circulation during the last 140 years, we used the recent 20CR Project version 2 (ref. 41 ), consisting of an ensemble of 56 realizations with $2^{\circ} \times 2^{\circ}$ gridded 6-hourly weather data from 1871 to 2010. Each ensemble member was performed using the NCEP/GFS (National Center for Environmental Prediction/Global Forecast System) atmospheric model, prescribing the monthly sea surface temperature and sea ice changes from HadISST as boundary conditions, and assimilating sea level pressure data from the International Surface Pressure Databank version 2 (http:// rda.ucar.edu/datasets/ds132.0). We used the ensemble mean to perform our analysis. An important caveat concerns the fact that few data were assimilated at the beginning of the reanalysis in the Southern Hemisphere, owing to the lack of available observations. Nevertheless, this product is one of the best data sets available for the evaluation of atmospheric circulation changes at a large scale in 
the Southern Hemisphere. Wind speed products were plotted over the Terre Adélie-George V Land (Fig. 5) and the offshore region $\sim 55-60^{\circ} \mathrm{S}$ (Supplementary Fig. 5).

\section{References}

1. Johnson, G. C. Quantifying Antarctic Bottom Water and North Atlantic Deep Water volumes. J. Geophys. Res. 113, C05027 (2008).

2. Jacobs, S. Bottom water production and its links with the thermohaline circulation. Antarct. Sci. 16, 427-437 (2004).

3. Tamura, T., Ohshima, K. I. \& Nihashi, S. Mapping of sea ice production for Antarctic coastal polynyas. Geophys. Res. Lett. 35, L07606 (2008).

4. Arrigo, K. R. \& van Dijken, G. L. Phytoplankton dynamics within 37 Antarctic coastal polynya systems. J. Geophys. Res. 108, 3271 (2003).

5. Barber, D. G. \& Massom, R. A. in Polynyas: Windows to the World Vol 74 (eds Smith, W. O. et al.) 1-54 (Elsevier Oceanography Series, 2007).

6. Rintoul, S. R. in Ocean, Ice, and Atmosphere: Interactions at the Antarctic Continental Margin Vol 75 (eds Jacobs, S. \& Weiss, R.) 151-171 (Antarctic Research Series, 1998)

7. Williams, G. D., Bindoff, N. L., Marsland, S. J. \& Rintoul, S. R. Formation and export of dense shelf water from the Adélie Depression, East Antarctica. J. Geophys. Res. 113, C04039 (2008).

8. Massom, R. A., Harris, P. T., Michael, K. J. \& Potter, M. J. The distribution of formative processes of latent heat polynyas in East Antarctica. Ann. Glaciol. 27, 420-426 (1998).

9. Lacarra, M., Houssais, M. N., Herbaut, C., Sultan, E. \& Beauverger, M. Dense shelf water production in the Adélie Depression 2004-2012: impact of the Mertz glacier calving. J. Geoph. Res. 119, 5203-5220 (2014).

10. Tamura, T., Williams, G. D., Fraser, A. D. \& Ohshima, K. I. Potential regime shift in decreased sea ice production after the Mertz Glacier calving. Nat. Commun. 3, 826 (2012).

11. Kusahara, K., Hasumi, H. \& Williams, G. Impact of Mertz Glacier Tongue calving on dense shelf water. Nat. Commun. 2, 159 (2011a).

12. Williams, G. D. \& Bindoff, N. L. Wintertime oceanography of the Adélie depression. Deep-Sea Res. Pt. II 50, 1373-1392 (2003).

13. Frezzotti, M., Cimbelli, A. \& Ferrigno, J. G. Ice-front change and iceberg behavior along Oates and George V coasts, Antarctica, 1912-96. Ann. Glaciol. 27, 643-650 (1998).

14. Massé, G. et al. Highly branched isoprenoids as proxies for variable sea ice conditions in the Southern Ocean. Antarct. Sci. 23, 487-498 (2011).

15. Armand, L. K., Crosta, X., Romero, O. \& Pichon, J.-J. The biogeography of major diatom taxa in Southern Ocean sediments: 1. Sea ice related species. Palaeogeog., Palaeoclim., Palaeoecol. 223, 93-126 (2005).

16. Crosta, X., Romero, O., Armand, L. K. \& Pichon, J.-J. The biogeography of major diatom taxa in Southern Ocean sediments: 2. Open ocean related species. Palaeogeog., Palaeoclim., Palaeoecol. 223, 66-92 (2005).

17. Denis, D. et al. Seasonal and sub-seasonal climate changes recorded in laminated diatom ooze sediments, Adélie Land, East Antarctica. Holocene 16, 1137-1147 (2006).

18. Presti, M., De Santis, L., Busetti, M. \& Harris, P. T. Late Pleistocene and Holocene sedimentation on the George V Continental Shelf, East Antarctica. Deep-Sea Res. Pt. II 50, 1441-1461 (2003).

19. Escutia, C. et al. Sediment distribution and sedimentary processes across the Antarctic Wilkes Land margin during the Quaternary. Deep-Sea Res. Pt. II 50, 3225-3226 (2003).

20. Dypvik, H. \& Harris, N. B. Geochemical facies analysis of fine-grained siliciclastics using $\mathrm{Th} / \mathrm{U}, \mathrm{Zr} / \mathrm{Rb}$ and $(\mathrm{Zr}+\mathrm{Rb}) / \mathrm{Sr}$ ratios. Chem. Geol. 181, 131-146 (2001)

21. Grinsted, A., Moore, J. C. \& Jevrejeva, S. Application of the cross wavelet transform and wavelet coherence to geophysical time series. Nonlin. Proc. Geophys. 11, 561-566 (2004).

22. Stammerjohn, S. E., Martinson, D. G., Smith, R. C., Yuan, X. \& Rind, D. Trends in Antarctic annual sea ice retreat and advance and their relation to El Niño-Southern Oscillation and Southern Annular Mode variability. J. Geophys. Res. 113, C03S90 (2008).

23. Dinniman, M. S., Klinck, J. M. \& Hofmann, E. E. Sensitivity of Circumpolar Deep Water Transport and Ice Shelf Basal Melt along the West Antarctic Peninsula to changes in the winds. Amer. Meteor. Soc. 25, 4799-4816 (2012).

24. Wuite, J. Spatial and Temporal Dynamics of Three East Antarctic Outlet Glaciers and Their Floating Ice Tongues 190, PhD thesis, Ohio State Univ. (2006).

25. Lescarmontier, L. et al. Vibration of the Mertz Glacier ice tongue, East Antarctica. J. Glaciol. 58, 665-676 (2012).

26. Legresy, B., Wendt, A., Tabacco, I., Remy, F. \& Dietrich, R. Influence of tides and tidal current on Mertz Glacier, Antarctica. J. Glaciol. 50, 427-435 (2004).

27. Marshall, G. J. Trends in the Southern Annular Mode from observations and reanalyzes. J. Clim. 16, 4134-4143 (2003).

28. Thompson, D. W. J. \& Wallace, J. M. Annular modes in the extratropical circulation. Part I: month-to-month variability. J. Clim. 13, 1000-1016 (2000).
29. Thompson, D. W. J. \& Solomon, S. Interpretation of recent Southern Hemisphere climate change. Science 296, 895-899 (2002).

30. Fogt, R. L., Perlwitz, J., Monaghan, A. J., Bromwich, D. H., Jones, J. M. \& Marshall, G. J. Historical SAM variability. part II: twentieth-century variability and trends from reconstructions, observations, and the IPCC AR4 models. J. Clim. 22, 5346-5365 (2009).

31. Villalba, R. et al. Unusual Southern Hemisphere tree growth patterns induced by changes in the Southern Annular Mode. Nat. Geosci. 5, 793-798 (2012).

32. Arblaster, J. M. \& Meehl, G. A. Contributions of external forcings to Southern Annular Mode Trends. J. Clim. 19, 2896-2905 (2006).

33. Jacobs, S. Observations of changes in the Southern Ocean. Phil. Trans. R. Soc. A 364, 1657-1681 (2006)

34. Massom, R. A. et al. Fast ice distribution in Adélie Land, East Antarctica: Interannual variability and implications for Emperor penguins (Aptenodytesforsteri). Mar. Ecol. Progr. Ser. 374, 243-257 (2009).

35. Hall, A. \& Visbeck, M. Synchronous variability in the Southern Hemisphere atmosphere, sea ice, and ocean resulting from the Annular Mode. J. Clim. 15, 3043-3057 (2002).

36. Meredith, M. P. \& Hogg, A. M. Circumpolar response of Southern Ocean eddy activity to a change in the Southern Annular Mode. Geophys. Res. Lett. 33, L16608 (2006).

37. Parish, N. J. P. \& Bromwich, D. H. Continental-scale simulation of the Antarctic katabatic wind regime. J. Clim. 4, 135-146 (1991).

38. Van der Broeke, M. R., van Lipzig, N. P. M. \& van Meijgaard, E Momentum budget of the East Antarctic atmospheric boundary layer: results of a Regional Climate Model. J. Atmos. Sci. 59, 3117-3129 (2002).

39. Egger, J. Slope winds and the axisymmetric circulation over Antarctica. J. Atmos. Sci. 42, 1859-1867 (1985).

40. Yasunari, T. \& Kodama, S. Intraseasonal variability of katabatic wind over east Antarctica and planetary flow regime in the southern hemisphere. J. Geophys. Res. 98, 13063-13070 (1993).

41. Compo, G. P. et al. The twentieth century reanalysis project. Q.J.R. Meteor. Soc 137, 1-28 (2011).

42. Van der Broeke, M. \& van Lipzig, N. P. M. Changes in Antarctic temperature wind and precipitation in response to Antarctic oscillation. Ann. Glaciol. 39, 119-126 (2004).

43. Massom, R. A. et al. An anomalous late-season change in the regional sea ice regime in the vicinity of the Mertz Glacier Polynya, East Antarctica. J. Geophys. Res. 108, 3212 (2003).

44. Massom, R. A. et al. Change and variability in East Antarctic sea ice seasonality, 1979/80-2009/10. PLoS ONE 8, e64756 (2013).

45. Schmidtko, S., Heywood, K. J., Thompson, H. \& Shigeru, A. Multidecadal warming of antarctic waters. Science 346, 1227-1231 (2014).

46. Martinson, D. G., Stammerjohn, S. E., Iannuzzi, R. A., Smith, R. C. \& Vernet, M. Western Antarctic Peninsula physical oceanography and spatiotemporal variability. Deep-Sea Res. Pt. II 55, 1964-1987 (2008).

47. Marini, C., Frankignoul, C. \& Mignot, J. Links between the Southern Annular Mode and the Atlantic Meridional Overturning Circulation in a Climate Model. J. Clim. 24, 624-640 (2011).

48. Orsi, A. H., Whitworth, III T. \& Nowlin, Jr W. D. On the meridional extent and fronts of the Antarctic Circumpolar Current. Deep-Sea Res. Pt. I 42, 641-673 (1995)

49. Klinck, J. M. \& Dinniman, M. S. Exchange across the shelf break at high southern latitudes. Ocean Sci. 6, 513-524 (2010).

50. St-Laurent, P., Klinck, J. M. \& Dinniman, M. S. On the role of coastal troughs in the circulation of Warm Circumpolar Deep Water on Antarctic Shelves. J. Phys Ocean 43, 51-64 (2013).

51. Bindoff, N. L., Rosenberg, M. A. \& Warner, M. J. On the circulation and water masses over the Antarctic continental slope and rise between 80 and $150^{\circ} \mathrm{E}$. Deep-Sea Res Pt. II 47, 2299-2326 (2000).

52. Aoki, S., Sasai, Y., Sasaki, H., Mitsudera, H. \& Williams, G. D. The cyclonic circulation in the Australian Antarctic basin simulated by an eddy resolving general circulation model. Ocean Dyn. 60, 743-757 (2010).

53. Maddison, E. J. et al. Post-glacial seasonal diatom record of the Mertz Glacier Polynya, East Antarctica. Mar. Micropal. 60, 66-88 (2006).

54. Rintoul, S. R. Rapid freshening of Antarctic Bottom Water formed in the Indian and Pacific oceans. Geophys. Res. Lett. 34, L06606 (2007)

55. Aoki, S., Rintoul, S., Ushio, S. \& Watanabe, S. Freshening of the Adélie Land Bottom Water near $140^{\circ}$ E. Geophys. Res. Lett. 32, L23601 (2005)

56. Previdi, M. \& Polvani, L. M. Climate system response to stratospheric ozone depletion and recovery. Q.J.R. Meteorol. Soc. 140, 2401-2419 (2014).

57. Migeon, S., Weber, O., Faugères, J.-C. \& Saint-Paul, J. SCOPIX: a new X-ray imaging system for core analysis. Geo-Mar. Lett. 18, 251-255 (1999).

58. Crosta, X. \& Koc, N. in Methods in Late Cenozoic Paleoceanography (eds Hilaire-Marcel, C. \& de Vernal, A.) 327-369 (Elsevier, 2007).

59. Kang, S.-H. \& Fryxell, G. A. Fragilariopsis cylindrus (Grunow) Krieger: the most abundant diatom in water column assemblages of Antarctic marginal ice edge zones. Pol. Biol. 12, 609-627 (1992). 
60. Froneman, J. W., McQuaid, G. D. \& Perissinotto, R. Biogeographic structure of the microphytoplankton assemblages of the south Atlantic and Southern Ocean during austral summer. J. Plankton Res. 17, 1791-1802 (1995b).

61. Johansen, J. R. \& Fryxell, G. A. The genus Thalassiosira (Bacillariophyceae): Studies on species occurring south of the Antarctic Convergence Zone. Phycologia 24, 155-179 (1985).

62. Gregory, T. Holocene sea ice-ocean-climate variability from Adélie Land, East Antarctica 237, PhD thesis, Cardiff University (2012).

63. Cunningham, W. L. \& Leventer, A. Diatom assemblages in surface sediments of the Ross Sea: relationship to present oceanographic conditions. Antarct. Sci. 10, 134-146 (1998).

64. Sinninghé Damsté, J. S. et al. The rise of the Rhizosolenoid diatoms. Science 304, 584-587 (2004).

65. Collins, L. G. et al. Evaluating highly branched isoprenoid (HBI) biomarkers as a novel Antarctic sea-ice proxy in deep ocean glacial age sediments. Quat. Sci. Rev. 79, 87-98 (2013).

66. Maddison, E. J., Pike, J. \& Dunbar, R. Seasonally laminated diatom-rich sediments from Dumont d'Urville Trough, East Antarctic Margin: LateHolocene Neoglacial sea-ice conditions. Holocene 22, 857-875 (2012).

67. Jansen, J. H. F., Van der Gaast, S. J., Koster, B. \& Vaars, A. J. CORTEX, a shipboard XRF-scanner for element analyses in split sediment cores. Mar. Geol. 151, 143-153 (1998).

68. Cavalieri, D. J., St. Germain, K. \& Swift, C. T. Reduction of weather effects in the calculation of sea ice concentration with the DMSP SSM/I. J. Glaciol. 41, 455-464 (1995).

69. Prokoph, A. \& El Bilali, H. Cross-Wavelet Analysis: a tool for detection of relationships between Paleoclimate Proxy Records. Math. Geosci. 40, 575-586 (2008).

70. Gong, D. \& Wang, S. Definition of Antarctic Oscillation Index. Geophys. Res. Lett. 26, 459-462 (1999).

\section{Acknowledgements}

This research was funded by the ERC StG ICEPROXY project (203441), the ANR CLIMICE project and FP7 Past4Future project (243908). P.C. is supported by a CNRS studentship. The French Polar Institute provided logistical support for sediment and data collection (IPEV projects 452 and 1010). This is ESF PolarClimate HOLOCLIP contribution $n^{\circ} 24$ and Past4Future contribution $n^{\circ} 83$.

\section{Author contributions}

X.C., G.M. and M.N.H. designed the study; P.C. performed diatom and XRF analyses; I.C. performed the biomarker analysis; D.S. performed atmospheric reanalysis; M.N.H and A.M. extracted daily sea ice concentrations and provided modern oceanographic insights; S.S. performed ${ }^{210} \mathrm{~Pb}$ analyses and developed the age model of the core; S.C., E.D. and V.M. helped with satellite images and spectral analyses; and all the authors contributed to the redaction of the manuscript.

\section{Additional information}

Supplementary Information accompanies this paper at http://www.nature.com/ naturecommunications

Competing financial interests: The authors declare no competing financial interests

Reprints and permission information is available online at http://npg.nature.com/ reprintsandpermissions/

How to cite this article: Campagne, P. et al. Glacial ice and atmospheric forcing on the Mertz Glacier Polynya over the past 250 years. Nat. Commun. 6:6642 doi: 10.1038/ ncomms7642 (2015). 